\title{
Implicações da Ciência e da Tecnologia na sociedade na visão dos alunos de Iniciação Científica de Ensino Médio da Instituição Federal de ensino
}

Washington Luiz da Costa washington.costa@ifpr.edu.br 0000-0002-1555-825

Instituto Federal do Paraná IFPR - Campus Londrina, Paraná, Brasil.

Andreia de Freitas Zompero andzomp@yahoo.com.br 0000-0002-5123-8073 Universidade Norte do Paraná UNOPAR - Londrina, Paraná,

Brasil.

\begin{abstract}
RESUMO
Este artigo faz parte de um estudo realizado com dez alunos do Ensino Médio, participantes de um projeto de Iniciação Científica no Instituto Federal do Paraná. Seu propósito foi aferir o conhecimento dos estudantes em relação ao entendimento de Ciência, Tecnologia e Sociedade, tendo como objetivo analisar a Influência da Ciência e Tecnologia sobre a Sociedade na compreensão dos alunos do Ensino Médio de uma Escola Federal, baseando-se nos documentos de ensino brasileiros e autores como, Bybee, Sasseron, Santos, Bazzo. Utilizamos para obtenção dos dados duas perguntas do questionário Canadense VOSTS. Na análise das respostas, elaboramos um referencial analítico que teve por base alguns pressupostos do $\mathrm{PCN}+$, a fim de avaliar o nível de Alfabetização Científica dos participantes. Suas respostas foram categorizadas em Adequadas, Plausíveis e Sem Opinião, subsidiadas pela escala Likert do Questionário Espanhol COCTS, atingindo 50\% de respostas consideradas adequadas na pergunta $1 \mathrm{e}$ $80 \%$ na pergunta 2.
\end{abstract}

PALAVRAS-CHAVE: Iniciação Científica. CTS. VOSTS. 


\section{INTRODUÇÃO}

A Iniciação Científica no Brasil foi constituída no interior das universidades, nas graduações, onde os alunos eram introduzidos na pesquisa sempre sob a supervisão de algum professor. Posteriormente, esse trabalho passou a ser desenvolvido com alunos do Ensino Médio, na Educação Básica. Nesse nível de ensino percebemos uma grande oportunidade para os estudantes realizarem pesquisas e com isso desenvolverem habilidades cognitivas relativas à aprendizagem em Ciências, como também contribuir para o avanço científico e tecnológico do país, pois sabemos que a Iniciação Científica nos países desenvolvidos caminha junto com o crescimento intelectual de sua nação.

No Ensino Médio percebemos a oportunidade da iniciação científica ser disseminada entre os participantes da comunidade escolar. É nessa etapa do ensino que a pesquisa de maneira sistematizada e contínua pode ser difundida. Observamos esta modalidade de ensino principalmente nas Instituições Federais que ofertam o Ensino Médio.

Alguns documentos de ensino como a Constituição da República Federativa do Brasil de 1988, a Lei de Diretrizes e Bases de 1996, o PCN + de 2002, o Programa do Ensino Médio Inovador de 2009, as Diretrizes Curriculares Nacionais Gerais para a Educação Básica, nas Resoluções №4 de 2010 e №2 de 2012, sugerem nos seus escritos, que a pesquisa científica seja iniciada e difundida na Educação Básica. Nesses documentos encontramos o respaldo necessário para o fomento da Pesquisa e indícios de que a Iniciação Científica deve ser inserida na proposta curricular do Ensino Médio. Nos documentos revisados são percebidas citações que se evidenciam o caráter científico, em síntese a pesquisa e a Iniciação Científica.

A Educação Científica tem como um de seus principais objetivos proporcionar a alfabetização científica aos estudantes. Esse processo tem como um de seus eixos a compreensão pelos alunos da relação entre Ciência, Tecnologia e as implicações para a sociedade (SASSERON; CARVALHO, 2011).

Consideramos que o processo de Iniciação Científica oportuniza momentos relevantes para as discussões referentes à perspectiva Ciência, Tecnologia e Sociedade (CTS). A implicação dos experimentos e avanços científicos e tecnológicos em relação à sociedade em que vivemos precisa ser melhor expressada e debatida nos bancos escolares.

Nesse sentido, consideramos que a Iniciação Científica deve possibilitar aos estudantes, além da compreensão dos processos da Ciência, também o entendimento de como os avanços científicos e tecnológicos impactam de maneira positiva ou negativa na sociedade.

Este estudo é parte de uma pesquisa mais ampla e buscamos responder qual o entendimento dos alunos do Ensino Médio que participaram do processo de Iniciação Científica, sobre as decisões referentes a Ciência e Tecnologia para a sociedade e como objetivo analisar a Influência da Ciência e Tecnologia sobre a sociedade na compreensão dos alunos do Ensino Médio de uma Escola Federal.

Refletimos sobre a importância da Iniciação Científica no Ensino Médio 
um cidadão reflexivo no exercício da sua autonomia e de seu discernimento crítico diante do contexto político, econômico e social em que está inserido.

\section{O CONCEITO CTS: CIÊNCIA, TECNOLOGIA E SOCIEDADE NO ENSINO}

Num breve histórico sobre a CTS, podemos salientar que esta perspectiva emergiu frente a problemas oriundos do pós-Segunda Guerra Mundial, evidenciando algumas preocupações como a degradação ambiental, o uso da Ciência e Tecnologia pela indústria bélica, o controle das armas nucleares, a regulação da engenharia genética, o controle da extensão artificial da vida e outras manifestações relacionadas ao modo que a sociedade tecnológica afetava a qualidade de vida (WALKS, 1990; AULLER; BAZZO, 2001) e se expandiu rapidamente em instituições educacionais de todos os níveis nos Estados Unidos, Canadá, Europa Ocidental, Austrália, Nova Zelândia e América do Sul.

Para Santos e Mortimer (2001, p.95),

O movimento CTS surgiu, então, em contraposição ao pressuposto cientificista, que valorizava a ciência por si mesmo, depositando uma crença cega em seus resultados positivos. A ciência era vista como uma atividade neutra, de domínio exclusivo de um grupo de especialistas, que trabalhava desinteressadamente e com autonomia na busca de um conhecimento universal, cujas consequências ou usos inadequados não eram de sua responsabilidade.

Nas universidades, começou a tomar forma entre os pesquisadores nas décadas de 1960 e 1970, vindo ao encontro da necessidade de inovações científicas e tecnológicas serem voltadas ao bem-estar social.

Apesar do avanço nas discussões sobre o movimento, nessa mesma época notamos um declínio por parte da opinião pública sobre os benefícios da C\&T. Para Bazzo (1998) foram períodos nebulosos em que o desenvolvimento científico e tecnológico passou de um extremo ao outro, indo do milagre à destruição. Nesse sentido, Cerezo et al. (2003) ressaltam que apesar do otimismo tão prometido, Ciência e Tecnologia decaem diante dos sucessivos desastres.

Nessa mesma época duas publicações foram fundamentais e iniciaram os debates sobre o uso da Ciência e Tecnologia.

[...] A estrutura das revoluções científicas, pelo físico e historiador da ciência Thomas Kuhn, e Silent spring, pela bióloga naturalista Rachel Carsons, ambas em 1962, potencializaram as discussões sobre as interações entre ciência, tecnologia e sociedade (CTS) (AULER; BAZZO, 2001).

Thomas Kuhn, na década de 1960, foi um dos autores que mais influenciaram na superação do positivismo lógico da ciência, algo que vinha permeando os pesquisadores desde o final da década de 1920. Para ele, a análise racionalista da ciência proposta pelo positivismo lógico era insuficiente, o que era necessário apelar para a dimensão social da ciência para explicar a produção, a manutenção e as mudanças das teorias científicas (BAZZO; LISINGEN; PEREIRA, 2003).

O positivismo, nessa época, continuava desenvolvendo vários aspectos da visão da ciência e "um traço marcante do positivismo se instaurou 
definitivamente com o Círculo de Viena, denominado positivismo lógico" (RAMOS; NEVES; CORAZZA, 2009, p. 3), unindo os métodos da lógica à postura empirista. Os positivistas lógicos da época utilizavam em suas abordagens o tradicional método hipotético-dedutivo e a verificação, a qual, por meio de reiterados testes, era considerada o melhor critério para determinar o quanto poderia ser válida uma teoria. Caso os testes confirmassem uma teoria, dir-se-ia que ela havia sido verificada (REALE, 1981; MAYR, 2008 apud RAMOS; NEVES; CORAZZA, 2009).

Para Bazzo, Linsingen e Pereira (2003, p.40-41), nessa perspectiva,

[...] a tecnologia era analisada como conhecimento prático que derivava diretamente da ciência (conhecimento teórico), [...] para os positivistas, as teorias científicas eram, sobretudo, conjuntos de enunciados que tratariam de explicar o mundo natural de um modo objetivo, racional e livre de qualquer valor externo à própria ciência.

Palacios et al. (2001) fizeram um breve histórico sobre marcos que influenciaram no declínio da ciência desde a década de 1950, dentre os quais destacamos, o lançamento do Sputinik I pela U.R.S.S. em 1957, primeiro satélite artificial ao redor da Terra, causando uma agitação social, política e educativa nos Estados Unidos e em outros países ocidentais; desastre do reator de Windscale na Inglaterra também em 1957, causando uma nuvem radioativa que se movimentou pela Europa Ocidental; tratado de limitação de testes nucleares em 1963; greves e manifestações públicas contra a guerra do Vietnam sobre o uso de armas químicas (Napalm) em 1968 e a manifestação da igreja, neste mesmo ano, contra a contracepção artificial da vida.

Após anos turbulentos, discussões acerca da CTS alertam para a necessidade de serem ampliadas para a população.

Para Cachapuz et al. (2005, p.28),

[...] a participação dos cidadãos na tomada de decisões é um facto positivo. [...] e reclamam um mínimo de formação científica que torne possível a compreensão dos problemas e das opções - que se podem e devem expressar com uma linguagem acessível.

Walks (1990, p.43) ressalta que o propósito da CTS seria, "promover a Alfabetização Científica em Ciência e Tecnologia, capacitando os cidadãos para participar do processo democrático da tomada de decisões".

Notamos ser desejável um cidadão capaz de se sensibilizar, de interagir e de participar ativamente das questões que afligem a população. Esta cidadania pressupõe ideais, crenças e atitudes de liberdade, solidariedade, respeito e compromisso com a vida em sociedade (GORDILLO, 2006 apud CONRADO; ELHANI, 2010).

Desse modo, podem colocar em prática o resultado do trabalho científico e tecnológico obtido em prol da mesma sociedade que o produziu, deixando de lado a inércia cognitiva e a alienação difundida por alguns setores da sociedade que ainda corroboram para isso. Alfabetizar os cidadãos em ciência e tecnologia é hoje uma necessidade do mundo contemporâneo (SANTOS; SCHNETZLER, 1997).

Sabemos que para avançarmos acerca do entendimento em CTS é necessário preparar o indivíduo para discutir diferentes pontos de vista e interesses e para 
refletir acerca das diferentes situações e dos fatos que ocorrem na sociedade e não apenas aceitá-los.

No ensino, o enfoque CTS busca a formação de indivíduos capazes de interagir nos debates sobre o desenvolvimento científico-tecnológico e influenciar nas decisões que afetam a sociedade, ter e manifestar opinião a seu respeito (PINHEIRO; SILVEIRA; BAZZO, 2007).

Para Pinheiro et al. (2009) a CTS estuda as inter-relações da Ciência, Tecnologia e Sociedade se voltando tanto para a investigação acadêmica quanto para as políticas públicas. Salientam também que o enfoque CTS procura entender os aspectos sociais do desenvolvimento da C\&T, seus benefícios e malefícios.

Na década de 1990 duas associações tiveram um papel de destaque no ensino CTS em âmbito secundário no mundo, a National Science Teachers Association nos Estados Unidos e a Association for Science Education na Grãbretanha, na Espanha a disciplina CTS tornou-se opcional nesta mesma época sendo também difundida nos bancos escolares secundaristas (PALACIOS et al., 2001).

No Brasil, o movimento teve início concomitantemente com os movimentos ambientalistas, tornando-se mais expressivo a partir do final da década de 1970 (CUNHA, 2008), quando as conversas sobre Ciência e Tecnologia ficaram restritas somente a alguns grupos de pessoas como cientistas, tecnólogos, filósofos e políticos. Observamos que nessa época iniciou-se,

[...] debates públicos acerca da importância do conhecimento da natureza da Ciência e atividade científica por parte dos cidadãos e, sobretudo, despertaram-se grupos sociais para a importância da compreensão das inter-relações Ciência, Tecnologia e Sociedade (TORRES, 2012, p. 2).

Nesse viés, algumas inquietações também contribuíram para fortalecer o surgimento do movimento CTS, sendo,

[...] cada vez mais evidente que a exploração desenfreada da natureza e os avanços científicos e tecnológicos obtidos não beneficiaram a todos. Enquanto poucos ampliaram potencialmente seus domínios, camuflados no discurso sobre a neutralidade da C\&T e sobre a necessidade do progresso para beneficiar as maiorias, muitos acabaram com os seus domínios reduzidos e outros continuam marginalizados, na miséria material e cognitiva (ANGOTTI; AUTH, 2001, p. 16).

Bazzo (2016, p.7), destaca que,

[...] por volta de 1970, o movimento CTS se traduzia em forte crítica ao modelo de desenvolvimento científico e tecnológico vigente por não ser condizente aos interesses do bem-viver de todas as pessoas pertencentes a diferentes classes sociais, nacionalidades, etnias, idades etárias e culturas. Época em que foram calcados exatamente o pensamento crítico e o debate em torno desse modelo cuja função primordial era atender aos interesses de uma minoria econômica e politicamente dominante.

$\mathrm{Na}$ atualidade, percebemos um sucateamento da instituição escolar a partir do olhar daqueles que se encontram envolvidos e preocupados com a educação. Em pleno século XXI, sistemas como o da comunicação, do ensino e o 
socioeconômico vigente contribuem para a manutenção desta situação caótica do ensino (COSTA, 2015, p.25).

Além dessa "deterioração da escola", Bazzo (2016) alerta para o fato de os professores estarem se entregando também a um pragmatismo exagerado, substituindo o ser pelo ter e parece ser, trocando a reflexão, o diálogo e a solidariedade pela produtividade e competitividade, prejudicando a pesquisa e contribuindo para a escassez da ênfase CTS dentro das salas de aula.

Para alguns autores, esse momento ruim vivido pela educação tem o amparo de atividades políticas pouco transparentes, políticas empresariais e industriais que desrespeitam e desvalorizam o trabalho humano, alienação social quanto às reais necessidades humanas, falta de igualdade e de justiça social, entre outros são fatores que contribuem para maior degradação socioambiental e têm sido mantidos ao longo das décadas (PINHEIRO; SILVEIRA; BAZZO, 2007).

Para Bazzo (2015, p. 105), "as avaliações da ciência e da tecnologia e de suas repercussões na sociedade precisam seguramente tomar rumos mais claros e intensos nas atividades de todas as escolas", ressalta ainda que,

[...] somente quando a alfabetização em ciência e tecnologia for entendida neste contexto mais amplo poderá haver uma esperança real de que a configuração do nosso mundo futuro será traçada por um eficiente controle público, de modo que os processos científicos e tecnológicos beneficiem verdadeiramente a humanidade (BAZZO, 2015, p.109).

Na Instituição Federal de ensino, precisamente o IFPR em uma cidade do norte do Paraná onde este estudo foi realizado, percebemos o compromisso dos docentes em possibilitar as discussões referentes à CTS no Ensino Médio. Nessa escola os alunos participam de projetos educacionais voltados ao desenvolvimento científico e tecnológico, em diversos setores, coordenados pelos docentes da instituição desde a sua criação com a Lei 11.892/08. A participação efetiva dos alunos em projetos dessa natureza oportuniza reflexões sobre a perspectiva CTS.

Ressaltamos a importância dessa participação dos alunos do Ensino Médio em projetos de pesquisa com propostas de desenvolvimento científico e tecnológico por possibilitar a eles o seu crescimento como cidadão crítico, autônomo, capaz de interferir positivamente na sociedade em que vive.

\section{O IFPR E O PROJETO DE INICIAÇÃO CIENTÍFICA AQUÁRIO EM REDE}

Os Institutos Federais no Brasil foram criados por meio da Lei no 11.892 de 29 de dezembro de 2008, com a missão de promover a educação profissional e tecnológica, pública, de qualidade, socialmente referenciada, por meio do ensino, pesquisa e extensão, visando à formação de cidadãos críticos, autônomos, além de ser referência em educação profissional, tecnológica e científica, reconhecida pelo compromisso com a transformação social, com o objetivo de diminuir esse abismo existente no processo de ensino-aprendizagem em relação à Ciência e Tecnologia e sua aplicação na sociedade.

De acordo com a Lei de criação e com seu Estatuto, o IFPR tem uma característica bem definida em relação à pesquisa praticada na Instituição, que é, "realizar e estimular a pesquisa aplicada, a produção cultural, o 
empreendedorismo, o cooperativismo e o desenvolvimento científico e tecnológico" (BRASIL, 2008).

No Instituto Federal o projeto "Aquário em Rede" chegou com a proposta de promover a inclusão da metodologia científica no dia a dia dos estudantes do Ensino Médio Técnico. É uma proposta que surgiu fundamentada para suprir três demandas: a necessidade de atuação de forma interdisciplinar e transdisciplinar; a carência de se trabalhar com tema integrador, atual, de relevância e de fácil contextualização com a vida dos estudantes e a ampliação da capacidade técnica dos alunos por meio da instrumentação técnica e científica acessível, com vistas à criação de banco de dados sobre o bioma amazônico.

Diante dessas demandas, o projeto foi estruturado para gerar as condições mínimas aos professores de diversas disciplinas do Ensino Médio Técnico do IFPR, oferecendo acesso a equipamentos específicos e recursos para a longevidade do projeto e tem como objetivo educacional, a formação de um banco de dados, capacitando estudantes do Ensino Médio para o levantamento, manuseio de equipamentos para análise e interpretação dos dados coletados, desenvolvendo a capacidade de trabalho em rede, por meio da troca de experiências com os outros campi. Em termos de oportunidade, o projeto viabiliza bolsas de Iniciação Científica para inclusão dos estudantes nos ambientes de pesquisa, na constante busca pelo desenvolvimento da técnica e pela construção do conhecimento como o intuito de despertar responsabilidades e auxiliar na verticalização do ensino.

\section{METODOLOGIA}

No presente trabalho, tratamos de uma pesquisa qualitativa do tipo interpretativa e faz parte de um estudo mais abrangente, que acompanhou durante o processo 10 (dez) alunos do projeto de Iniciação Científica intitulado "Aquário em Rede". Os participantes eram do curso de Informática integrado ao Ensino Médio, dos segundos e terceiros anos e atuavam no projeto em horário de contraturno, manipulando e acompanhando os dados do aquário como temperatura e pH da água, alimentação dos peixes, monitoramento 24 horas por câmera via Blog. Durante o processo disponibilizamos materiais para leituras e pesquisas realizadas para a familiarização dos estudantes com o projeto. Ao final do estudo foram elencadas sugestões aos coordenadores para o aprimoramento do processo.

Para obtenção dos dados deste estudo, com o intuito de analisar a compreensão dos alunos sobre a Influência da Ciência e Tecnologia na Sociedade, os estudantes responderam a duas questões do questionário internacional denominado VOSTS - Views on science-technology-society (AIKENHEAD; RYAN; FLEMING, 1989), quanto ao entendimento das relações CTS.

Para escolha das questões do referido questionário, tomamos por base as orientações contidas no PCN+ do Ensino Médio (2002), Orientações Educacionais Complementares aos Parâmetros Curriculares Nacionais das Ciências da Natureza, Matemática e suas Tecnologias, concernentes às competências esperadas que os alunos do Ensino Médio desenvolvam quanto à compreensão da Ciência e Tecnologia na atualidade, portanto, a relação CTS (Ciência, Tecnologia e Sociedade). As competências estão elencadas no quadro 1. 
Dessa maneira, os dados foram organizados com base no questionário VOSTS e em confronto às competências propostas pelo PCN+ (Quadro 1). As análises foram realizadas com base nos resultados obtidos por meio do questionário.

Quadro 1 - Contextualização sociocultural do PCN+

\begin{tabular}{|c|}
\hline Contextualização sociocultural \\
\hline Ciência e tecnologia na atualidade \\
$\begin{array}{c}\text { Reconhecer e avaliar o desenvolvimento tecnológico contemporâneo, suas relações com } \\
\text { as ciências, seu papel na vida humana, sua presença no mundo cotidiano e seus } \\
\text { impactos na vida social. }\end{array}$
\end{tabular}

Fonte: PCN+ (BRASIL, 2002, p. 32).

Para analisar e tratar os dados obtidos por meio da frequência das escolhas de respostas dos alunos para caracterização do VOSTS, elencamos o questionário COCTS - Cuestionario de Opiniones de Ciencia, Tecnología y Sociedad (MANASSERO; VÁZQUEZ, 1998; VÁSQUEZ; MANASSERO, 1999; MANASSERO; VÁZQUEZ; ACEVEDO, 2001, 2003), onde se destacam as categorias, Ingênuas ou Inadequadas; Plausíveis ou Parcialmente Aceitáveis e Adequadas ou Apropriadas Totalmente, que também oferecem suporte validando o instrumento de categorização que utilizamos neste trabalho.

Quadro 2 - Escala Likert do Questionário Espanhol COCTS

\begin{tabular}{|c|c|c|c|c|c|c|c|c|}
\hline \multicolumn{3}{|c|}{ LMENOS ADEQUADAS } & \multicolumn{4}{c|}{ MAIS ADEQUADAS $\rightarrow$} \\
\hline \multicolumn{3}{|c|}{$\begin{array}{c}\text { Ingênuas ou } \\
\text { Inadequadas }\end{array}$} & \multicolumn{3}{c|}{$\begin{array}{c}\text { Plausíveis, } \\
\text { parcialmente aceitáveis }\end{array}$} & \multicolumn{3}{c|}{$\begin{array}{c}\text { Adequadas, } \\
\text { apropriadas totalmente }\end{array}$} \\
\hline $\begin{array}{c}\text { Totalmente } \\
\text { ingênuas }\end{array}$ & $\begin{array}{c}\text { Bastante } \\
\text { ingênuas }\end{array}$ & Ingênuas & $\begin{array}{c}\text { Pouco } \\
\text { plausivel }\end{array}$ & Plausivel & $\begin{array}{c}\text { Bastante } \\
\text { plausivel }\end{array}$ & Adequadas & $\begin{array}{c}\text { Bastante } \\
\text { adequadas }\end{array}$ & $\begin{array}{c}\text { Totalmente } \\
\text { adequadas }\end{array}$ \\
\hline 1 & 2 & 3 & 4 & 5 & 6 & 7 & 8 & 9 \\
\hline
\end{tabular}

Fonte: Questionário COCTS (MANASSERO; VÁZQUEZ; ACEVEDO, 2003).

O COCTS é um questionário espanhol que contém 100 itens que foram adaptados do questionário VOSTS - Views on Science-Technology-Society, que é uma ferramenta valiosa para avaliação do ponto de vista dos alunos e das razões de suas respostas.

É relevante destacar que as respostas do questionário VOSTS não buscam o verdadeiro ou falso, o certo e o errado. Para Vásquez, Manassero e Acevedo (2005, p. 10), "não tem nada a ver com um esquema absoluto, pois é relativo, de acordo com a compreensão dialética da história, epistemologia e sociologia da ciência". Dentro de cada item existe uma ampla gama de posicionamentos diferentes sobre o assunto em questão. Os questionados podem definir livremente suas escolhas e não existe modelo de resposta a ser seguido.

Portanto, estabelecemos a categorização que foi aplicada com base no COCTS. Adicionamos outra categoria a qual denominamos "Sem Opinião (SO)", para melhor classificar as respostas dos alunos. Dessa maneira, as categorias adaptadas e que utilizaremos neste estudo são:

- Plausível (P): Quando as opções de resposta não forem totalmente adequadas e expressarem somente alguns aspectos aceitáveis;

- Adequada (A): Quando as opções de respostas forem consideradas adequadas; 
- Sem Opinião (SO): Quando o aluno não apresentar opinião sobre o assunto.

As duas perguntas escolhidas e aplicadas do questionário VOSTS com o formato de múltipla escolha, começando com um cabeçalho, continha uma afirmativa inicial seguida por uma lista de afirmações que oferecem uma gama de diferentes respostas fundamentadas para o assunto levantado.

\section{ANÁLISE DAS RESPOSTAS}

Nessa análise é importante esclarecer que os números que aparecem na tabela 1 correspondem à quantidade de alunos que assinalaram a alternativa, que conforme o COCTS é indicado por Plausível, Adequada e Sem Opinião. A fim de manter o sigilo sobre os participantes desta pesquisa, optamos por identificálos com a letra $A$ mais o número do aluno, ex: A1, A2, A3, facilitando a visualização das respostas.

Os resultados dessa análise são relevantes, pois podem proporcionar um novo olhar sobre a Iniciação Científica e suas aplicações em relação à CTS no Instituto Federal do Paraná, apontando alguns indicativos quanto à formação CTS dos alunos e, assim, proporcionar o aprimorando do processo pedagógico com relação aos projetos científicos desenvolvidos na Instituição.

Tabela 1 - Resultados da categorização da questão 1 - referente à Influência da Ciência e Tecnologia sobre a Sociedade do questionário VOSTS

\begin{tabular}{|c|c|c|c|c|}
\hline 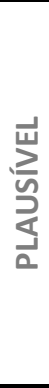 & 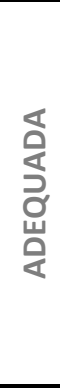 & 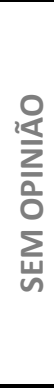 & 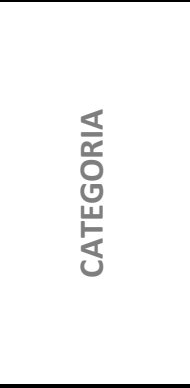 & $\begin{array}{l}1 \text { - Cientistas e engenheiros devem ser os únicos a } \\
\text { decidir sobre a produção mundial de alimentos e } \\
\text { distribuição de alimentos (por exemplo, como } \\
\text { cortar a planta, onde melhor plantá-las, como } \\
\text { transportar os alimentos de forma eficiente, como } \\
\text { obter comida para quem precisa, etc), porque os } \\
\text { cientistas e engenheiros são as pessoas que } \\
\text { conhecem os fatos melhores. Sua posição, } \\
\text { basicamente é: }\end{array}$ \\
\hline 1 & & & PLAUSÍVEL & $\begin{array}{l}\text { A. porque eles têm a formação e os fatos que lhes } \\
\text { dão uma melhor compreensão do problema. }\end{array}$ \\
\hline 1 & & & PLAUSÍVEL & $\begin{array}{l}\text { B. porque eles têm o conhecimento e podem tomar } \\
\text { melhores decisões do que, burocratas do governo } \\
\text { ou empresas privadas que tem interesses escusos. }\end{array}$ \\
\hline \multirow[t]{4}{*}{2} & & & PLAUSÍVEL & $\begin{array}{l}\text { C. porque eles têm a formação e os fatos que lhes } \\
\text { dão uma melhor compreensão, mas o público deve } \\
\text { ser envolvido, seja informado ou consultado. }\end{array}$ \\
\hline & 5 & & ADEQUADA & $\begin{array}{l}\text { D. a decisão deve ser feita em partes iguais, pontos } \\
\text { de vista de cientistas e engenheiros, outros } \\
\text { especialistas, bem como o público informado } \\
\text { devem ser considerados nas decisões que afetam a } \\
\text { nossa sociedade. }\end{array}$ \\
\hline & & & & $\begin{array}{l}\text { E. o governo deve decidir, porque a questão é } \\
\text { basicamente política, mas os cientistas e } \\
\text { engenheiros deveriam dar conselhos. }\end{array}$ \\
\hline & & & & $\begin{array}{l}\text { F. o público deve decidir, porque a decisão afeta a } \\
\text { todos, mas os cientistas e engenheiros deveriam } \\
\text { dar suas opiniões. }\end{array}$ \\
\hline
\end{tabular}




\begin{tabular}{l|l|l|l|l}
\hline & & & $\begin{array}{l}\text { G. o público deve decidir, porque o público serve } \\
\text { como um controle sobre os cientistas e } \\
\text { engenheiros. Cientistas e engenheiros têm visões } \\
\text { idealistas e estreitas, assim, dão pouca atenção às } \\
\text { consequências. }\end{array}$ \\
\hline & & & & \begin{tabular}{l} 
H. eu não entendo. \\
\hline
\end{tabular} \\
\hline & 1 & $\begin{array}{l}\text { I. eu não sei o suficiente sobre o assunto para fazer } \\
\text { uma escolha. }\end{array}$ \\
\hline
\end{tabular}

Fonte: Do autor.

Nesta questão №1 do VOSTS são consideradas adequadas, plausíveis e sem opinião as respostas a seguir distribuídas no quadro 3.

Quadro 3 - Categorização da questão 1

\begin{tabular}{|c|c|}
\hline CATEGORIAS DA QUESTÃO 1 & RESPOSTAS \\
\hline ALTERNATIVAS CONSIDERADAS ADEQUADAS & $\mathrm{D}$ \\
\hline ALTERNATIVAS CONSIDERADAS PLAUSÍVEIS & $\mathrm{A}, \mathrm{B}, \mathrm{C}, \mathrm{E}, \mathrm{F}, \mathrm{G}$ \\
\hline ALTERNATIVAS CONSIDERADAS SEM OPINIÃO & $\mathrm{H}, \mathrm{I}, \mathrm{J}$ \\
\hline
\end{tabular}

Fonte: Do autor.

$\mathrm{Na}$ alternativa considerada Adequada, referente influência da Ciência e Tecnologia sobre a Sociedade, tomamos por base as discussões de Bybee e Deboer (1994), Fourez (1994), Bybee (1995), Hurd (1998), Jiménez-Aleixandre, Bugallo Rodríguez e Duschl (2000), Yore, Bisanz e Hand (2003), Lemke (2006), Lorenzeti e Delizoicov (2001), no que se refere ao ensino promover nos alunos a compreensão da Ciência e Tecnologia e suas implicações na Sociedade, enquanto cidadãos.

Nas alternativas consideradas Plausíveis, fundamentamo-nos em autores como Auler e Delizoicov (2001), que apontam a necessidade da superação de uma percepção ingênua, Sasseron (2008), Sasseron e Carvalho (2011), que discorrem sobre ser imprescindível o entendimento dos alunos nas questões CTS e Bazzo et al. (2003), que alertam sobre a importância da formação dos docentes no enfoque CTS.

Para finalizar as categorizações, na alternativa considerada Sem Opinião, optamos pela discussão apresentada por Chalmers (1993).

A questão 1 (Tabela 1) correspondente à Influência da Ciência e Tecnologia sobre a Sociedade do VOSTS. Cinco alunos assinalaram o item D considerado adequado. Para as respostas consideradas Plausíveis, um aluno assinalou o item $A$, outro assinalou o item $B$ e dois alunos escolheram o item $C$ e na categorização Sem Opinião, um estudante assinalou o item J.

\section{Questão 1 (um):}

Cientistas e engenheiros devem ser os únicos a decidir sobre a produção mundial de alimentos e distribuição de alimentos (por exemplo, como cortar a planta, onde melhor plantá-las, como transportar os alimentos de forma eficiente, como obter comida para quem precisa, etc), porque os cientistas e engenheiros são as pessoas que conhecem os fatos melhores. Sua posição, basicamente é: 
A. porque eles têm a formação e os fatos que lhes dão uma melhor compreensão do problema.

Essa resposta foi assinalada pelo aluno A3. Entendemos que esta escolha é Plausível (P) por ser superficial e pouco adequada quanto à compreensão CTS, pois exclui os demais participantes da sociedade, como especialistas e o público que poderiam tecer opiniões importantes sobre a produção, estocagem e distribuição dos alimentos.

É possível que a relação Ciência, Tecnologia, Sociedade (CTS) não esteja clara ao participante questionado, apresentando dúvidas no esclarecimento das responsabilidades provocadas pela questão um.

Salientamos que, é necessário um embasamento teórico mais eficaz com relação ao ensino da Ciência, Tecnologia e Sociedade. Ressaltamos também que a formação dos professores para o ensino desse aporte teórico aos alunos torna-se essencial, pois como argumentam Auler e Delizoicov (2001, p. 8) colocam, "a superação de uma percepção ingênua e mágica da realidade exige, cada vez mais, uma compreensão dos sutis e delicados processos de interação entre CTS".

Portanto, o conhecimento adquirido pelo professor sobre a CTS pode ajudar na superação dessa percepção ingênua do aluno, fazendo-o compreender as relações e interações que existem na sociedade na qual está inserido.

B. porque eles têm o conhecimento e podem tomar melhores decisões do que burocratas do governo ou empresas privadas que tem interesses escusos.

O aluno A4 assinalou esta opção de resposta que classificamos como Plausível (P) por ser restrita e superficial ao problema apresentado no enunciado da questão. Admitimos que em nossa sociedade, atualmente, existam pessoas gabaritadas, com várias competências que podem contribuir com soluções aceitáveis em relação à produção de alimentos.

Entendemos, então, que esse aluno, em relação à Influência da Ciência e Tecnologia sobre a Sociedade precisa de mais amparo teórico e de melhores ferramentas de ensino para facilitar-Ihe a compreensão sobre a CTS.

C. porque eles têm a formação e os fatos que Ihes dão uma melhor compreensão, mas o público deve ser envolvido, seja informado ou consultado.

Dois participantes da pesquisa responderam esta questão, os alunos A2 e A6, considerada Plausível (P) por carecer de um maior número de detalhes. Expandindo a discussão em diversos níveis sociais, a participação da sociedade nas decisões sobre o rumo da produção de alimentos é extremamente importante, pois apenas informar e consultar sem ter o poder para decisões torna o processo estanque e pouco objetivo.

Observamos que faltam a esses alunos subsídios e pressupostos teóricos para avançar o conhecimento em relação ao assunto abordado. Entendemos que esta variação pode ter sido causada por uma desatenção no momento de responder o questionário ou por falta de aporte teórico, visto que os enunciados são muito parecidos dentro do mesmo item de categorização referente à Influência da Ciência e Tecnologia sobre a Sociedade. Sugerimos que seja aplicado um novo questionário no futuro para ser confrontado com a aplicação atual. 
D. a decisão deve ser feita em partes iguais, pontos de vista de cientistas e engenheiros, outros especialistas, bem como o público informado devem ser considerados nas decisões que afetam a nossa sociedade.

Cinco participantes da pesquisa assinalaram essa opção de resposta, alunos A1, A7, A8, A9 e A10. Esta escolha é considerada Adequada (A), refletindo o desejo da população em relação aos problemas levantados, portanto, a participação de todos frente à discussão é fundamental.

Consideramos que as afirmativas de respostas por serem idênticas em seus escritos, podem ter influenciado alguns alunos nas opções de escolha, uma vez que tiveram como base a resposta anterior. Vale destacar que cinco alunos optaram por outro tipo de resposta. Concluímos também que os alunos que optaram por outra alternativa ainda carecem de um entendimento maior sobre o assunto CTS e sobre sua devida aplicação em prol da sociedade. Esses participantes, no momento da aplicação do questionário, podem ter tido um entendimento e uma melhor compreensão em relação ao assunto proposto.

Reconhecemos a importância da Alfabetização Científica para a compreensão da tríade CTS, principalmente para o entendimento desta questão referente à produção e distribuição de alimentos, presente no questionário.

J. nenhuma dessas opções corresponde ao meu ponto de vista básico.

O aluno A5 respondeu esta alternativa. Admitimos ser Sem Opinião (SO), por não apresentar nenhuma proposta para a regulação da produção de alimentos. Consideramos que a compreensão do aluno carece de elementos que possibilitem uma análise para tomada de decisão a respeito do que foi perguntado.

A seguir apresentamos, na tabela 2, os resultados da questão 2 respondida pelos estudantes.

Tabela 2 - Resultados da categorização da questão 2 - referente à Influência da Ciência e Tecnologia sobre a Sociedade do questionário VOSTS.

\begin{tabular}{l|l|l|l}
\hline & & & $\begin{array}{l}\text { 2 - Cientistas e engenheiros devem ser os únicos a } \\
\text { decidir sobre a poluição atmosférica brasileira } \\
\text { (por exemplo, as emissões industriais de dióxido } \\
\text { de enxofre, aparelhos de controle de poluição } \\
\text { para seu carro ou caminhão, as emissões de gases } \\
\text { ácidos de poços de petróleo, etc), porque os } \\
\text { cientistas e engenheiros são as pessoas que } \\
\text { conhecem os fatos melhores. Sua posição, } \\
\text { basicamente é: }\end{array}$ \\
\hline 1 & & PLAUSíVEL & $\begin{array}{l}\text { A. porque eles têm a formação e os fatos que lhes } \\
\text { dão uma melhor compreensão do problema. }\end{array}$ \\
\hline 1 & & $\begin{array}{l}\text { B. porque eles têm o conhecimento e podem } \\
\text { tomar melhores decisões do que burocratas do } \\
\text { governo ou empresas privadas que tem interesses } \\
\text { escusos. }\end{array}$ \\
\hline
\end{tabular}




\begin{tabular}{|c|c|c|}
\hline & & ser envolvido, seja informado ou consultado. \\
\hline 8 & ADEQUADA & $\begin{array}{l}\text { D. a decisão deve ser feita em partes iguais, pontos } \\
\text { de vista de cientistas e engenheiros, outros } \\
\text { especialistas, bem como o público informado } \\
\text { devem ser considerados nas decisões que afetam a } \\
\text { nossa sociedade. }\end{array}$ \\
\hline & & $\begin{array}{l}\text { E. o governo deve decidir, porque a questão é } \\
\text { basicamente política, mas os cientistas e } \\
\text { engenheiros devem dar conselhos. }\end{array}$ \\
\hline & & $\begin{array}{l}\text { F. o público deve decidir, porque a decisão afeta a } \\
\text { todos, mas os cientistas e engenheiros deveriam } \\
\text { dar suas opiniões. }\end{array}$ \\
\hline & & $\begin{array}{l}\text { G. o público deve decidir, porque o público serve } \\
\text { como um controle sobre os cientistas e } \\
\text { engenheiros. Cientistas e engenheiros têm visões } \\
\text { idealistas e estreitas, assim, dão pouca atenção às } \\
\text { consequências. }\end{array}$ \\
\hline & & H. eu não entendo. \\
\hline & & $\begin{array}{l}\text { I. eu não sei o suficiente sobre o assunto para fazer } \\
\text { uma escolha. }\end{array}$ \\
\hline & & $\begin{array}{l}\text { J. nenhuma dessas opções corresponde ao meu } \\
\text { ponto de vista básico. }\end{array}$ \\
\hline
\end{tabular}

Fonte: Do autor.

Nesta questão №2 do VOSTS são consideradas Adequadas, Plausíveis e Sem Opinião as respostas a seguir distribuídas no quadro 2 .

Quadro 4 - Categorização da questão 2

\begin{tabular}{|c|c|}
\hline CATEGORIAS DA QUESTÃO 2 & RESPOSTAS \\
\hline ALTERNATIVAS CONSIDERADAS ADEQUADAS & $\mathrm{D}$ \\
\hline ALTERNATIVAS CONSIDERADAS PLAUSÍVEIS & $\mathrm{A}, \mathrm{B}, \mathrm{C}, \mathrm{E}, \mathrm{F}, \mathrm{G}$ \\
\hline ALTERNATIVAS CONSIDERADAS SEM OPINIÃO & $\mathrm{H}, \mathrm{I}, \mathrm{J}$ \\
\hline
\end{tabular}

Fonte: Do autor

$\mathrm{Na}$ alternativa considerada Adequada referente à Influência da Ciência e Tecnologia sobre a sociedade, apoiamo-nos nas discussões de Santos e Mortimer (2001), Vieira e Bazzo (2007), Sorpreso (2008), Cunha (2008) e Conrado e El-Hani (2010) sobre a promoção de debates reflexivos na escola, na formação integral de um aluno crítico e reflexivo diante da sociedade na qual está inserido.

Nas alternativas consideradas Plausíveis, tomamos por base as discussões de Santos (1999), que salienta um ensino não engessado, tendo como meta a Educação Científica e Tecnológica e em Sasseron e Carvalho (2011), que destacam a importância da Alfabetização Científica na Educação Básica, e a necessidade de oferecer ao aluno o apoio necessário para participação nas decisões da vida em sociedade. 
A questão dois (Tabela 2) correspondente à Influência da Ciência e Tecnologia sobre a sociedade do VOSTS. Oito alunos assinalaram a resposta D, considerada Adequada. Para as alternativas consideradas Plausíveis, um aluno assinalou a opção B e um aluno assinalou a opção C. Para a categorização Sem Opinião, não houve respostas assinaladas.

Questão 2 (dois):

Cientistas e engenheiros devem ser os únicos a decidir sobre a poluição atmosférica brasileira (por exemplo, as emissões industriais de dióxido de enxofre, aparelhos de controle de poluição para seu carro ou caminhão, as emissões de gases ácidos de poços de petróleo, etc), porque os cientistas e engenheiros são as pessoas que conhecem os fatos melhores. Sua posição, basicamente é:

B. porque eles têm o conhecimento e podem tomar melhores decisões do que burocratas do governo ou empresas privadas que tem interesses escusos.

Apenas um aluno A4 optou por essa solução, que consideramos ser Plausível $(P)$, ou seja, razoável, não totalmente aceita, pois de acordo com essa resposta somente cientistas e engenheiros possuem conhecimento suficiente para a solução dos problemas apontados, não levando a discussão para outros âmbitos da sociedade civil. Faltam informações pertinentes em relação à responsabilidade das decisões a serem tomadas sobre a poluição atmosférica brasileira.

O aluno que assinalou essa opção ainda carece de subsídios para a formulação concreta de uma resposta mais elaborada sobre a Influência da Ciência e da Tecnologia na sociedade.

Diante do exposto, ressaltamos que a continuidade do participante no projeto provavelmente lhe dará o suporte e a condição necessária para atingir esta meta proposta por Santos (1999) em relação ao conhecimento cientifico e tecnológico.

C. porque eles têm a formação e os fatos que Ihes dão uma melhor compreensão, mas o público deve ser envolvido, seja informado ou consultado.

Somente o aluno A2 optou por essa resposta que consideramos ser Plausível $(P)$, pois a população em geral não pode ser apenas informada ou consultada. A participação e o envolvimento de todos os setores da sociedade em conselhos deliberativos fazem-se mais do que necessários numa república democrática, uma vez que compete aos conselhos analisarem e buscarem soluções para a contenção da poluição, sendo essa uma das propostas da Alfabetização Científica.

Em relação ao participante da pesquisa que assinalou esta alternativa, pode haver uma defasagem em relação ao aporte necessário sugerido para o entendimento e compreensão da questão no que diz respeito à participação do público.

Consideramos que a participação dos alunos na Iniciação Científica "deve desenvolver em uma pessoa a capacidade de organizar seu pensamento de maneira lógica, além de auxiliar na construção de uma consciência mais crítica em relação ao mundo que a cerca" (SASSERON; CARVALHO, 2011, p. 65). Portanto, afirmamos que a constante participação do aluno no projeto Aquário 
em Rede Ihe trará melhor compreensão e entendimento sobre questões relacionadas à Influência da Ciência e da Tecnologia na sociedade.

D. a decisão deve ser feita em partes iguais, pontos de vista de cientistas e engenheiros, outros especialistas, bem como o público informado devem ser considerados nas decisões que afetam a nossa sociedade.

Nesta alternativa, oito alunos assinalaram essa opção de resposta, alunos A1, A3, A5, A6, A7, A8, A9 e A10. Consideramos ser uma opção Adequada (A), por refletir o desejo da população em relação aos problemas levantados no enunciado da pergunta do questionário. A participação de todos é fundamental frente à discussão.

Em relação à escolha feita pelos participantes da pesquisa, apontamos o fato de que na escola pesquisada são abordadas as questões sociais e ambientais como saúde e transporte público eficiente; temas de cunho tecnológico; energia renovável; comunicação e assuntos de caráter ambiental; poluição; desperdício de alimentos; descarte do lixo; agrotóxico; esgoto. Consideramos que diante do exposto, a reflexão dos alunos ficou amparada por meio de assuntos ligados diretamente a esta temática. Santos e Mortimer (2001) aconselham que sejam propostas nas escolas atividades que possibilitem aos alunos refletirem sobre problemas sociocientíficos associados à realidade, visando, além do ensino conceitual, formar atitudes, valores e preparar o aluno para questionar, participar e construir coletivamente respostas para problemas sociais.

Detectamos nessa questão a necessidade de acrescentarmos o enfoque "Ambiente" na discussão da perspectiva CTS, para um maior aprofundamento em alternativas que envolvem a CTSA, pois esta abordagem tem sido cada vez mais difundida nos currículos escolares por buscar propiciar o desenvolvimento de maior consciência acerca das interações entre Ciência, Tecnologia, Sociedade e Ambiente, e rompe com a imagem neutra da ciência e desenvolve a capacidade crítica do aluno e de atuação frente a problemas de seu contexto social.

\section{CONSIDERAÇÕES FINAIS}

O entendimento das relações entre Ciência, Tecnologia e suas implicações para a Sociedade (CTS), tem sido uma preocupação no que tange às questões do ensino da Educação Científica na atualidade. Neste artigo tivemos por objetivo conhecer e analisar a Ciência e a Tecnologia e sua influência na sociedade na visão dos alunos do Instituto Federal que participam do projeto intitulado "Aquário em Rede".

As análises das respostas dos participantes, registradas no questionário VOSTS, instrumento de coleta de dados utilizado nesta pesquisa, indicaram o percurso da Iniciação Científica no Ensino Médio do IFPR. Procuramos, de forma imparcial, abordar temas relevantes como a produção mundial de alimentos e a poluição, questões de cunho científico, tecnológico e social.

Percebemos que o questionário VOSTS, além de ser um instrumento validado na comunidade científica, oferece uma grande amplitude na opção de respostas e, dessa maneira, permitiu-nos identificar aspectos relativos à compreensão dos alunos quanto à CTS. 
Nas respostas à questão 1 , notamos a interação dos estudantes com relação à relevância do tema. Durante a análise de dados, foi possível perceber que esta questão estimula o desejo dos alunos de participarem das decisões sobre problemas que envolvem a Ciência, Tecnologia e Sociedade, fator que contribui para as escolhas adequadas de resposta, sendo que $50 \%$ dos alunos (tabela 1) optaram por esta categorização, demonstrando uma total segurança em relação ao assunto que aborda a produção e distribuição dos alimentos. Outros $40 \%$ dos participantes assinalaram as alternativas Plausíveis, não trazendo, assim, preocupações relevantes para o apontamento de sugestões referentes ao projeto pesquisado. Apenas $10 \%$ dos participantes escolheram o item Sem Opinião, o que demonstra a necessidade de subsídios teóricos e explicações objetivas sobre a CTS.

Quanto à questão 2 , especificamente, $80 \%$ dos alunos assinalaram a opção considerada Totalmente Adequada demonstrando, assim, que a CTS é compreendida pelos participantes da pesquisa em relação às decisões sobre a "poluição atmosférica brasileira". Apenas $20 \%$ dos alunos (Tabela 2), optaram por respostas consideradas incompletas e Plausíveis, o que indica a necessidade de mais aporte teórico e discussões relevantes sobre o tema levantado acerca da CTS.

Salientamos que os resultados das análises foram discutidos com os orientadores do projeto e pudemos apontar algumas das lacunas percebidas durante o processo, orientando que seja feito um melhor aprofundamento teórico sempre no início de cada ano letivo para os alunos que ingressam em projetos de Iniciação Científica na instituição.

Em relação às duas questões analisadas que abordam as "decisões de cientistas e engenheiros", as respostas foram consideradas satisfatórias, coerentes e com poucas variações. Ressaltamos ainda a existência de uma linha tênue entre uma escolha Adequada e uma Plausível, quando consideramos o curto caminho a ser percorrido pelo estudante com relação a sua compreensão sobre a CTS.

Ressaltamos, portanto, a importância da Iniciação Científica e a necessidade de sua difusão no Ensino Médio, por oportunizar aos alunos conhecer e vivenciar processos da Ciência, como também poderá contribuir satisfatoriamente para a compreensão e entendimento dos alunos para questões pertinentes à Ciência, Tecnologia e suas implicações para sociedade. 


\title{
Implications that science and technology have on society according to scientific research initiation high school students of a federal institute of education
}

\begin{abstract}
This article is part of a study carried out with ten high school students, participants of a project of Scientific Initiation at the Instituto Federal do Paraná. Its purpose was to assess their knowledge regarding the science, technology and society understanding, aiming to analyze the Influence of Science and Technology on the Society in the understanding of the students of the High School of a Federal School, based on the Brazilian teaching documents and authors as, Bybee, Sasseron, Santos, Bazzo. We used two questions from the Canadian VOSTS questionnaire to obtain the data. In the analysis of the answers, we elaborated an analytical reference that was based on some assumptions of the PCN +, in order to evaluate the level of Scientific Literacy of the participants. Their answers were categorized as Adequate, Plausible and No Opinion, subsidized by the Likert scale of the Spanish COCTS Questionnaire, reaching 50\% of answers considered adequate in question 1 and $80 \%$ in question 2 .
\end{abstract}

KEYWORDS: Scientific Initiation. CTS. VOSTS. 


\section{REFERÊNCIAS}

AIKENHEAD, G. S.; RYAN, A. G.; FLEMING, R. W. Views on science-technologysociety (VOSTS). Form CDN, Canadá, Mc.5, 1989.

ANGOTTI, J. A. P.; AUTH, M. A. Ciência e tecnologia: implicações sociais e o papel da educação. Ciência \& Educação, Bauru, v. 7, n. 1, p. 15-27, 2001.

ARAÚJO, M. S. T.; SILVA, P. A. V. B. Abordagem de temas de educação ambiental sob o enfoque CTSA no Ensino médio no município de Barueri-SP. In: SEMINÁRIO HISPANO BRASILEIRO - CTS, 2., 2012, [S. I.]. Anais... [S. I.], 2012.

AULER, D.; BAZZO, W. A. Reflexões para a implementação do movimento CTS no contexto educacional Brasileiro. Ciência \& Educação, Bauru, v. 7, n. 1, p. 1-13, 2001.

AULER, D.; DELIZOICOV, D. Alfabetização científico-tecnológica para quê?. Ensaio: Pesquisa em Educação em Ciências, Belo Horizonte, v. 3, n. 1, jun. 2001.

BAZZO, W. A. Ciência, Tecnologia e Sociedade: e o contexto da educação tecnológica. Ed. da UFSC, Florianópolis, 1998.

Ciência, Tecnologia e Sociedade: e o contexto da educação tecnológica.

Ed. da UFSC, Florianópolis, 5a ed., 2015.

Ponto de Ruptura Civilizatória: a Pertinência de uma Educação

"Desobediente". Revista Iberoamericana CTS, Buenos Aires, v. 11, n. 33, 2016.

BAZZO, W. A. et al. Introdução aos estudos CTS: o que e ciência, tecnologia e sociedade? Cadernos de Ibero-América, OEI, 2003.

BAZZO, W. A.; LINSINGEN, I. V.; PEREIRA, L. T. V. Introdução aos estudos CTS (ciência, tecnologia e sociedade). Cadernos de Ibero-América, Madri: OEI Organização dos estados Ibero-americanos para a educação, a ciência e a cultura, 2003.

BRASIL. Constituição Federal do Brasil de 1988. Disponível em:

$<$ http://www.planalto.gov.br/ccivil_03/Constituicao/Constituicao.htm>. Acesso em: 1 agosto 2017. 
Educação, Ciência e Tecnologia, e dá outras providências. Disponível em: <http://www.planalto.gov.br/ccivil_03/_ato2007-2010/2008/lei/l11892.htm>. Acesso em: 1 agosto 2017.

Lei no 9.394, de 20 de Dezembro de 1996. Estabelece as diretrizes e bases da educação nacional. Disponível em: <http://www.planalto.gov.br/ccivil_03/leis/l9394.htm>. Acesso em: 2 agosto 2017.

Portaria no 971, de 9 de outubro de 2009. Programa ensino médio inovador. Disponível em: $<$ http://portal.mec.gov.br/index.php?option=com_content\&view=article\&id=134 39>. Acesso em: 2 agosto 2017.

Resolução № 2, de 30 de Janeiro 2012. Diretrizes Curriculares Nacionais para o Ensino Médio. Disponível em:

<http://portal.mec.gov.br/index.php?option=com_content\&view=article\&id=174 17\&Itemid=866>. Acesso em: 2 agosto 2017.

Resolução № 4, de 13 de Julho de 2010b. Define Diretrizes Curriculares Nacionais Gerais para a Educação Básica. Disponível em:

<http://portal.mec.gov.br/dmdocuments/rceb004_10.pdf>. Acesso em: 2 agosto 2017.

. Secretaria da Educação Média e Tecnológica. PCN+: ensino médio: orientações educacionais complementares aos Parâmetros Curriculares Nacionais. Brasília: MEC, 2002.

BYBEE, R. W. Achieving scientific literacy. The Science Teacher, [S. I.], v. 62, n. 7, p. 28-33, 1995.

BYBEE, R. W.; DEBOER, G. E. Research on goals for the science curriculum. In: GABEL, D. L. (Ed.). Handbook of research in science teaching and learning. New York: McMillan, p. 357-387, 1994.

CACHAPUZ, A. et al. A necessária renovação do ensino de ciências. Cortez, São Paulo, 2005.

CEREZO, J. A. L. et al. Introdução aos estudos CTS: (ciência, tecnologia e sociedade). OEI, Madrid, 2003. 
CONRADO, D. M.; EL-HANI, C. N. Formação de cidadãos na perspectiva CTS: reflexões para o ensino de ciências. In: SIMPÓSIO NACIONAL DE CIÊNCIA E TECNOLOGIA, 2., 2010, Ponta Grossa. Anais... Ponta Grossa: UTFPR, 2010.

COSTA, W. L. A CTS (Ciência, Tecnologia e Sociedade) na compreensão dos alunos que participam da iniciação científica no Instituto Federal do Paraná. 2015. 114 f. Dissertação (Mestrado em Metodologias para o Ensino de Linguagens e suas Tecnologias) - Centro de Pesquisa em Educação e Tecnologia, Universidade Norte do Paraná, Londrina, 2015.

CUNHA, A. M. Ciência, tecnologia, e sociedade na óptica docente: construção e validação de uma escala de atitudes. 2008. Dissertação (Mestrado) - Faculdade de Educação, Universidade Estadual de Campinas, Campinas, 2008.

FOUREZ, G. L'alphabétisation scientifique et technique: problematique (table ronde). In: JOURNÉES INTERNATIONALES SUR LA COMMUNICATION L'EDUCATION ET LA CULTURE SCIENTIFIQUES ET INDUSTRIELLES, 16., [S. I.]. Actas... Chamonix, 1994.

HURD, P. D. Scientific literacy: new minds for a changing world. Science Education, London, v. 82, n. 3, p. 407-416, 1998.

JIMÉNEZ-ALEIXANDRE, M. P.; BUGALLO RODRÍGUEZ, A.; DUSCHL, R. A. "Doing the Lesson" or "Doing Science": Argument in High School Genetics", Science Education, London, v. 84, p. 757-792, 2000.

LEMKE, J. L. Investigar para el futuro de la educación científica: nuevas formas de aprender, nuevas formas de vivir. Enseñanza de las Ciencias, Barcelona, v. 24, n. 1, p. 5-12, 2006.

LORENZETTI, L.; DELIZOICOV, D. Alfabetização científica no contexto das séries iniciais, Ensaio - Pesquisa em Educação em Ciências, v.3, n.1, 37-50, 2001.

MANASSERO, M. A.; VÁZQUEZ, A. Opinions sobre ciència, tecnologia i societat. Palma de Mallorca: Govern Balear, Conselleria d'Educació, Cultura i Esports, 1998.

MANASSERO, M. A.; VÁZQUEZ, A.; ACEVEDO, J. A. Avaluació del temes de ciència, tecnologia i societat. Palma de Mallorca: Conselleria d'Educació i Cultura. 2001. 
PALACIOS, E. M. G. et al. Ciencia, tecnología y sociedad: una aproximación conceptual. Cuadernos de Iberoamérica, OEI, Madrid, 2001

PINHEIRO, N. A.; SILVEIRA, R. M.; BAZZO, W. A. A relevância do enfoque CTS para o contexto do ensino médio. Ciência \& Educação, Bauru, v. 13, n. 1, p. 71-84, 2007.

PINHEIRO et al. O contexto científico-tecnológico e social acerca de uma abordagem crítico-reflexiva: perspectiva e enfoque. Revista Iberoamericana de Educación, OEI, n. 49-1, 2009.

RAMOS, F. P.; NEVES, M. C. D.; CORAZZA, M. J. Os paradigmas da ciência moderna e pós-moderna e as concepções de professores-pesquisadores. In: ENCONTRO NACIONAL DE PESQUISA EM EDUCAÇÃO EM CIÊNCIAS, 7., 2009, Florianópolis. Anais... Florianópolis, 2009.

REALE, G. História da filosofia: o positivismo. Paulus, São Paulo, 1981.

SANTOS, M. E. Desafios pedagógicos para o século XXI: suas raízes em forças de mudança de natureza científica, tecnológica e social. Livros Horizonte, Lisboa, 1999.

SANTOS, W. L. P.; MORTIMER, E. F. Tomada de decisão para ação social responsável no ensino de ciências. Ciência e Educação, Bauru, v. 7, n. 1, p. 95111, 2001.

SANTOS, W. L. P.; SCHNETZLER, R. P. Educação em química: compromisso com a cidadania. UNIJUÍ, Ijuí,1997.

SASSERON, L. H. Alfabetização científica no ensino fundamental: estrutura e indicadores deste processo em sala de aula. 2008. Tese (Doutorado) - Faculdade de Educação da USP, São Paulo, 2008.

SASSERON, L. H.; CARVALHO, A. M. P. Alfabetização científica: uma revisão bibliográfica. Investigações em Ensino de Ciências, Porto Alegre, v. 16, n. 1, p. 5977, 2011.

SORPRESO, T. P. Organização de episódios de ensino sobre a "questão nuclear" para o ensino médio: foco no imaginário de licenciados. 2008. Dissertação (Mestrado) - Faculdade de Educação, Universidade Estadual de Campinas, Campinas, 2008. 
TORRES, A. C. C. Desenvolvimento de courseware com orientação CTS para o ensino básico. 2012. Tese (Doutorado) - Universidade de Aveiro, Aveiro, 2012.

VÁZQUEZ ALONSO, A.; MANASSERO, M. A.; ACEVEDO, J. A. Análisis cuantitativo de ítems complejos de opción múltiple en ciencia, tecnología y sociedad: Escalamiento de ítems. Revista Electrónica de Investigación Educativa, Baja, v. 7, n. 1, 2005.

VÁZQUEZ, A.; MANASSERO, M. A. New response and scoring models for the "views on sciencetechnology-society" instrument (VOSTS). International Journal of Science Education, London, v. 21, p. 231-247, 1999.

VIEIRA, K. R. C. F.; BAZZO, W. A. Discussões acerca do aquecimento global: uma proposta CTS para abordar esse tema controverso em sala de aula. Ciência \& Ensino, Campinas, v. 1, n. esp. 2007.

WALKS, L. J. Educación en ciencia, tecnología y sociedad: origenes, desarrollos internacionales y desafíos actuales. In: MEDINA, M., SANMARTíN, J. (Eds.). Ciencia, tecnología y sociedad: estudios interdisciplinares en la univeridade, en la educacíon y en la gestión política y social. Barcelona, Anthropos; Leioa: Universidad del País Vasco, p. 42-43, 1990.

YORE, L. D.; BISANZ, G. L. E.; HAND, B. M. Examining the literacy component of science literacy: 25 years of language arts and science research. International Journal of Science Education, London, v. 25, n. 6, p. 689-725, 2003.

Recebido: 2016-09-28

Aprovado: 2017-08-30

DOI: $10.3895 /$ rbect.v10n3.4689

Como citar:

COSTA, W. L.: ZOMPERO, A. F. Implicações da ciência e da tecnologia na sociedade na visão dos alunos

de iniciação científica de ensino médio da instituição federal de ensino. Revista Brasileira de Ensino de

Ciência e Tecnologia, v. 10, n. 3, 2017. Disponível em:

$<$ https://periodicos.utfpr.edu.br/rbect/article/view/4689>. Acesso em: XXXX

Correspondência: Washington Luiz da Costa - washington.costa@ifpr.edu.br

Direito autoral: Este artigo está licenciado sob os termos da Licença Creative Commons-Atribuição 4.0 Internacional. 